\title{
The Mine Geostress Testing Methods and Design
}

\author{
Jin-Long Su, Ping-Song Zhang, Rong-Xin Wu \\ School of Earth and Environment, Anhui University of Science and Technology, Huainan, China \\ Email: sujinlong0710@126.com
}

Received 25 September 2014; revised 20 October 2014; accepted 17 November 2014

Copyright (C) 2014 by authors and Scientific Research Publishing Inc.

This work is licensed under the Creative Commons Attribution International License (CC BY). http://creativecommons.org/licenses/by/4.0/

c) (i) Open Access

\begin{abstract}
The mine geostress measurement is the indispensable key to safe and efficient production of the mine. Currently, stress relief method, hydraulic fracturing method and acoustic emission method are widely used in mine geostress test fields. As deficiencies of the above several methods, the author designed a detailed borehole acoustic program for the tectonic fault conditions of a mine in Huainan, and got geostress parameter values according to the combination of site measured velocity values and laboratory tests.
\end{abstract}

\section{Keywords}

Mine Geostress, Borehole Acoustic Method, Test Program

\section{Introduction}

As a natural stress in the earth without engineering disturbance, the geostress is the basic force which causes deformation and failure of underground or opencast geotechnical engineering. So the geostress measurement is a necessary prerequisite to determine engineering properties of soil mechanics which carry out rock stability analysis and make the program of the excavation of geotechnical engineering scientific [1]. On mining terms, with demand for mineral resources increasing, many mines have entered the production phase of 800 - $1000 \mathrm{~m}$ deep where coal seams and geological occurrence has happened great changes and geological structure is very complex. Deep mining faces high stress, high temperature gradient, high osmotic pressure, which are fundamental differences characterized by shallow mining rock, that bring a series of problems to excavation and support of roadway. The mine geostress is the prime reason to cause the deformation and damage of country rock and supporting structure. Only master the geostress conditions of project area, you can reasonably determine the general location of the mine, select the appropriate mining methods and determine the optimum cross-sectional shape roadway position, supporting structure, forms, time in the tunnel and slope. So then you can minimize the cost of surrounding rock control and improve the economic benefit of the mine. 


\section{The Mine Geostress Testing Methods}

In-situ stress test theory and technology has been the important research content of the rock mechanics and engineering and geological engineering and other disciplines. At present there are many kinds of in-situ stress measurement methods, the different classified standards also have different results. According to the measuring principle, it can be divided into three categories: the first methods which can inverse geostress are based on measuring strain and deformation of rock mass in combination with rock mechanics properties; the second is the geophysical methods which are based on the determination of acoustic emission, seismic wave velocity and the resistivity that are caused by geostress; the final methods use the information provided by the geological structure and damage status of underground rock mass. In mine in-situ stress measurement, stress relief method, hydraulic fracturing method and acoustic emission method have achieved wide application. Deep rock geostress can be measured by borehole acoustic method, therefore it also gets people's attention.

\subsection{Stress Relief Method}

The stress relief method is developed and studied for the longest time, its technical degree has closed to maturity in in-situ stress measurement methods so far with a strong applicability and reliability. It is based on the theory of elasticity, the certain scope of the rock mass is regarded as homogeneous and isotropic elastic body completely. The basic procedure of borehole stress relief method is as follows: Firstly a main borehole is drilled in the rock. Secondly, a homocentric pilot hole is drilled at the bottom of the main borehole. Thirdly, a probe for stress measurement is installed into the pilot hole. Then the main borehole continues to relieve the rock stresses surrounding the probe which is used to sense and record the deformations of the borehole in course of stress relief operation. Finally, the in-situ rock stresses are calculated according to the obtained data [2].

The stress relief method is very strict with the integrity of the rock. It is difficult to success in the mine deep geostress measurement as strata have stratified phenomenon and rock core are difficult to gain with the problem of the differences of temperature, humidity, lithologic which cause a large discrete test results. At present, the stress release method measuring depth still cannot meet the requirement of the mine deep in-situ stress measurement, and spend large manpower and material resources and high cost.

\subsection{Hydraulic Fracturing Method}

Hydro-fracturing method is a robust technique for stress measurement in deep rock mass. It measure in-situ stress according to the following steps: firstly, a small segment of drilling is filled with high pressure water, the pressure inside hole increases gradually. Secondly, the borehole wall is fractured in the hole when pressure in the hole reached the maximum named $\mathrm{Pb}$. In order to keep fractures open, the pressure in the hole will eventually reach a constant value. Thirdly, the pressure drops rapidly after water injection is stopped, the pressure is reduced slowly as fracture is closed when the pressure is drop to the critical value which is instantaneous closing pressure named Ps. We can get the open pressure named Pr and instantaneous closed pressure again when the water is injected again after the first pressure is relieved completely. Finally, the in-situ rock stresses are calculated according to the fracture direction recorded by instrument [3].

\subsection{Acoustic Emission Method}

Kaiser Effect is a phenomenon that a large number of elastic wave is released quickly in rock mass when the current external load is greater than the maximum load in the history, stress at the turning point is the history maximum stress. The three-dimensional stress state is measured by Kaiser Point which can be obtained through the specimen made from the original rock core under uniaxial loading [4].

The application of acoustic emission method is greatly limited due to the following reasons. The stress value measured by acoustic emission method is maximum stress in the history rather than in-situ geostress values. Kaiser Effect can also be caused by the sliding friction of the existing fracture surface in acoustic emission experiment. High strength brittle rock has better effect than low strength plastic rock with high porosity.

\section{Design of Borehole Acoustic Method}

\subsection{Station and Borehole Layout}

The elastic wave velocity in rock mass is changed in different pressure conditions. The relative rate of change of 
wave velocity which can reach $10^{-2}-10^{-3}$ /MPa provides theory of borehole acoustic method. The program aimed at the F72 reverse fault which impacts on coal face of a mine in Hainan is designed to explore the geostress condition under the influence of the fault. It provide basis for selecting the appropriate mining methods and determinations of the optimum cross-sectional shape roadway, coal face position, supporting structure parameters and supporting time, etc., according to the study of original stress field distribution and its spatial evolution law. So then it can be effective to minimize the cost of surrounding rock control and improve the economic benefit of the mine.

The result is better with more number of sonic drilling when the test area is under a little impact. The observation station in which contains 3 drill holes is selected by thought of the site construction conditions, drilling technology and equipment testing scope restrictions combining with the condition of 1142 (1) coal face. Drilling borehole layout shall is required to meet the technical requirements, Table 1 is showed as overall design for the detection holes parameters, Figure 1 is a borehole layout diagram.

The observation system used the direct wave method of one-transmitter and receivers to make fan-shaped observation. While the source is fixed in a design point to seismic signals in one drill hole, the detector are used to receive the signals in the other two drill hole. So you can get two vertical wave velocity floor plans determined by a point and two straight lines. After moving the source in turn equidistantly, the wave velocity value measured in a line.

Table 1. Drilling design parameter table.

\begin{tabular}{ccccc}
\hline \multirow{2}{*}{$\begin{array}{c}\text { Construction of } \\
\text { section }\end{array}$} & Angle $\left(^{\circ}\right)$ & Drilling parameters & Dopth $(\mathrm{m})$ \\
\cline { 2 - 5 } & 0 & Orientation $\left(^{\circ}\right)$ & 100 & Place the receivers \\
No. 1 drilling & 0 & 90 & 80 & Place the sources \\
No. 2 drilling & -5 & 90 & 100 & Place the receivers \\
No. 3 drilling & & 90 &
\end{tabular}

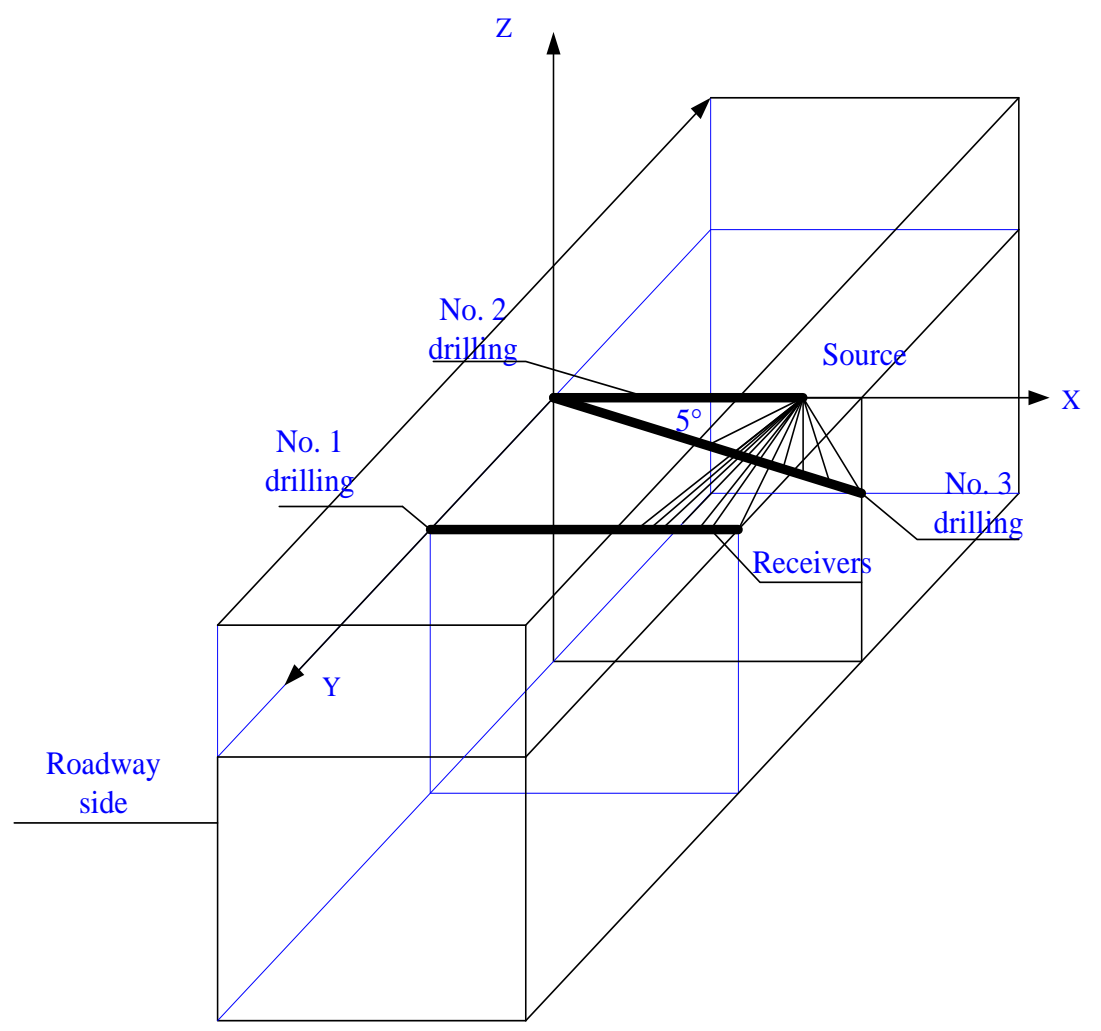

Figure 1. The borehole layout diagram. 


\subsection{Determination of Acoustic Ellipse}

Wave velocity vector scattered on the three-dimensional coordinate system in the different directions is obtained by fan-shaped observation in the selected rock mass. The measuring point velocity vector is moved to the center of the ellipsoid circle which is the center of the measurement. In order to calculate easily, we take XOY plane as horizontal plane and $\mathrm{Z}$ axis for the vertical direction, which named three main wave velocity values in calculating acoustic ellipsoid. The wave velocity value obtained by the detector in one drill hole is used as the acoustic ellipse axial length in this direction. The vertical and horizontal plane acoustic ellipse can be got according to the linear regression of coordinates and the measured wave coordinate values. The wave velocity values in three principal stress directions are obtained from acoustic ellipsoid up to above two acoustic ellipses at the source site [5].

\subsection{The Indoor Experiment}

The experiments were divided into two cases contained uniaxial compression test and triaxial test. Uniaxial compression test system is conducted in common material testing machine with two pairs of P-wave transducers to measure the wave velocities and strain gauges to make strain measurements in both axial and lateral directions. In triaxial test, three pairs of pressurized P-wave transducer converters and strain gauges are installed to measure the wave velocities and stress and strain on the three principal stress directions. Triaxial compression experiments were conducted by the following three steps:

Experiment 1: The load is increased equally step by step on the three principal stress directions until the specimen damage. The minimum principal stress is determined from the curve of wave velocity and the stress value on three directions.

Experiment 2: The load is increased equally step by step on the three principal stress directions until the load reaches the minimum principal stress. Then keeping the load on the minimum principal stress direction is constant, the load on other two directions are increased equally step by step until the specimen damage. The intermediate principal stress is determined from the curve of wave velocity and the stress value on three directions.

Experiment 3: Firstly, the load is increased equally step by step on the three principal stress directions until the load reaches the minimum principal stress. Secondly keeping the load on the minimum principal stress direction is constant, the load on other two directions are increased equally step by step until the load reaches the intermediate stress. Then the load on the maximum principal stress direction is increased until the specimen damage. The maximum principal stress is determined from the curve of wave velocity and the stress value on three directions.

\section{Data Processing}

According to the indoor experiment, we can make the wave velocity curve changing with stress as the following figure. By fitting the experimental data and the analysis of the graphic, we establish the following relation between the wave velocity and stress.

$$
\begin{gathered}
\mathrm{V}_{\mathrm{P} 1}-\mathrm{V}_{\mathrm{P} 2}=\mathrm{K}_{2}\left(\sigma_{1}-\sigma_{2}\right) \\
\mathrm{V}_{\mathrm{P} 2}-\mathrm{V}_{\mathrm{P} 3}=\mathrm{K}_{1}\left(\sigma_{2}-\sigma_{3}\right) \\
\mathrm{V}_{\mathrm{P} 3}=\mathrm{V}_{\mathrm{P} 0}+\sigma_{3} \mathrm{~K}_{1}
\end{gathered}
$$

$\mathrm{K}_{1}$ and $\mathrm{K}_{2}$ said dependence coefficient of wave velocity and stress under triaxial stress. With the determation of acoustic ellipsoid, we can get the values and orientations of the three principal stress (Figure 2).

\section{Conclusion}

Borehole acoustic method uses acoustic wave velocity which measured by seismic instrument to invert value and direction of principal stress indirectly. Compared with other geostress measurements, it has characteristics of wide range of applicability, simple manipulation, low cost and high measuring accuracy. In this paper, the authors formulated the detailed test program for the special geological conditions in a mine according to the basic principle of borehole acoustic method, and used it to do field test work. This design has a certain practical significance and reference value for the mine geostress measurement. 


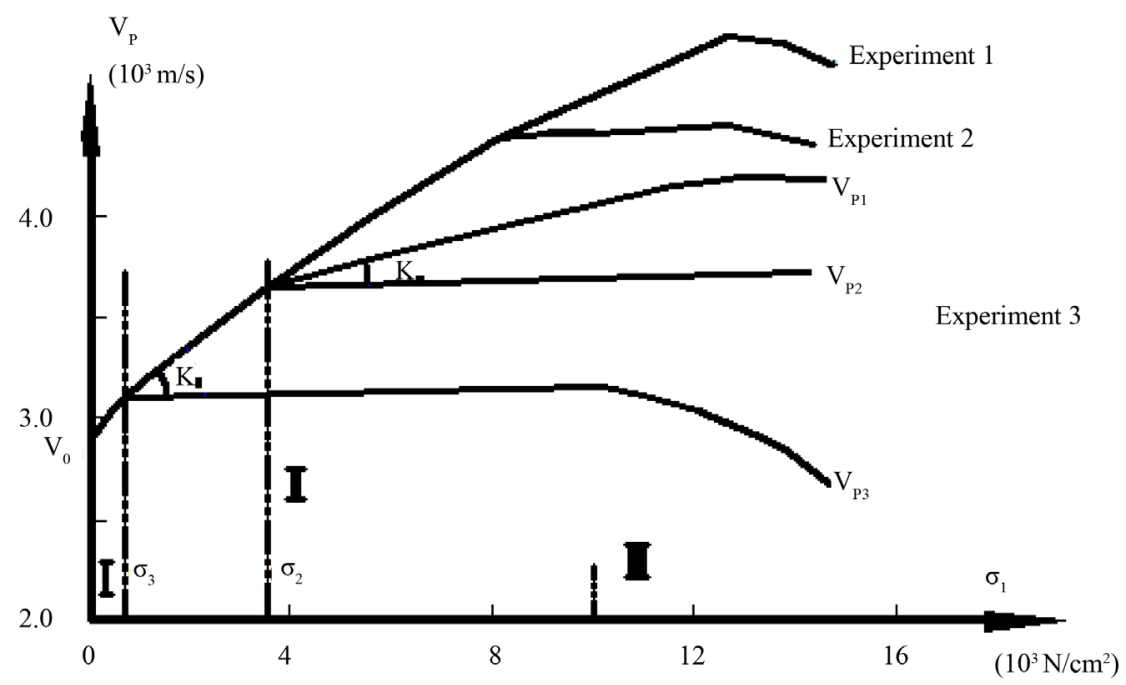

Figure 2. The wave velocity curve changing with stress.

\section{References}

[1] Yu, X.F., Zheng, Y.R., Liu, H.H., et al. (1983) Stability Analysis of Surrounding Rock of Underground Engineering. Coal Industry Publishing House, Beijing.

[2] Chen, J.X., Wang, H.L. and Wang, X.Q. (2010) Over Coring Method by Using the Set of Hole Is Applied for Mine In-Situ Stress Measurement. Shanxi Coking Coal Science and Technology, 2, 31-33.

[3] You, M.Q. (2005) Study of Hydraulic Fracturing Method to Measure In-Situ Stress Method. Journal of Geotechnical Engineering, 3, 350-353.

[4] Chu, J. (2008) Acoustic Emission Prediction of Rock Fracture and Application to Geostress Survey of Kasier Effect. Master's Thesis, Shandong University of Science and Technology, Qingdao.

[5] Wang, H.T. and Xian, X.F. (1988) The Study on Characteristics of Elastic Wave Propagation in Rocks under Complicated Stress State. Journal of Chongqing University (Natural Science), 5, 52-59. 
Scientific Research Publishing (SCIRP) is one of the largest Open Access journal publishers. It is currently publishing more than 200 open access, online, peer-reviewed journals covering a wide range of academic disciplines. SCIRP serves the worldwide academic communities and contributes to the progress and application of science with its publication.

Other selected journals from SCIRP are listed as below. Submit your manuscript to us via either submit@scirp.org or Online Submission Portal.
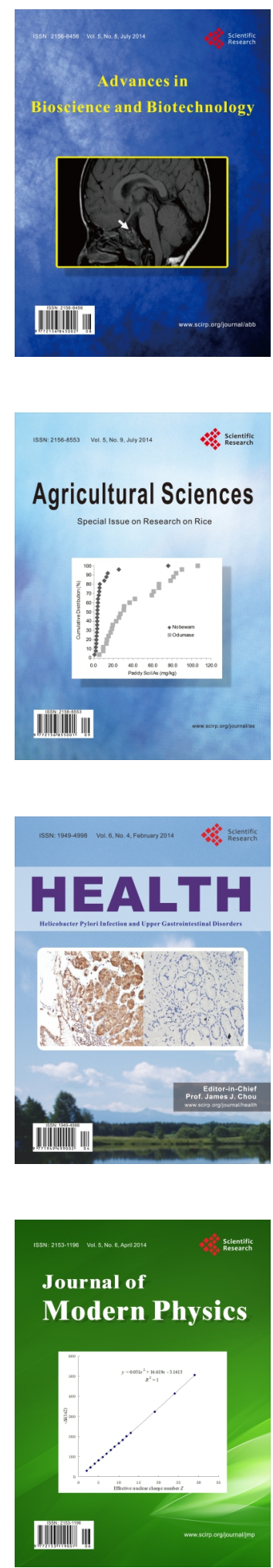
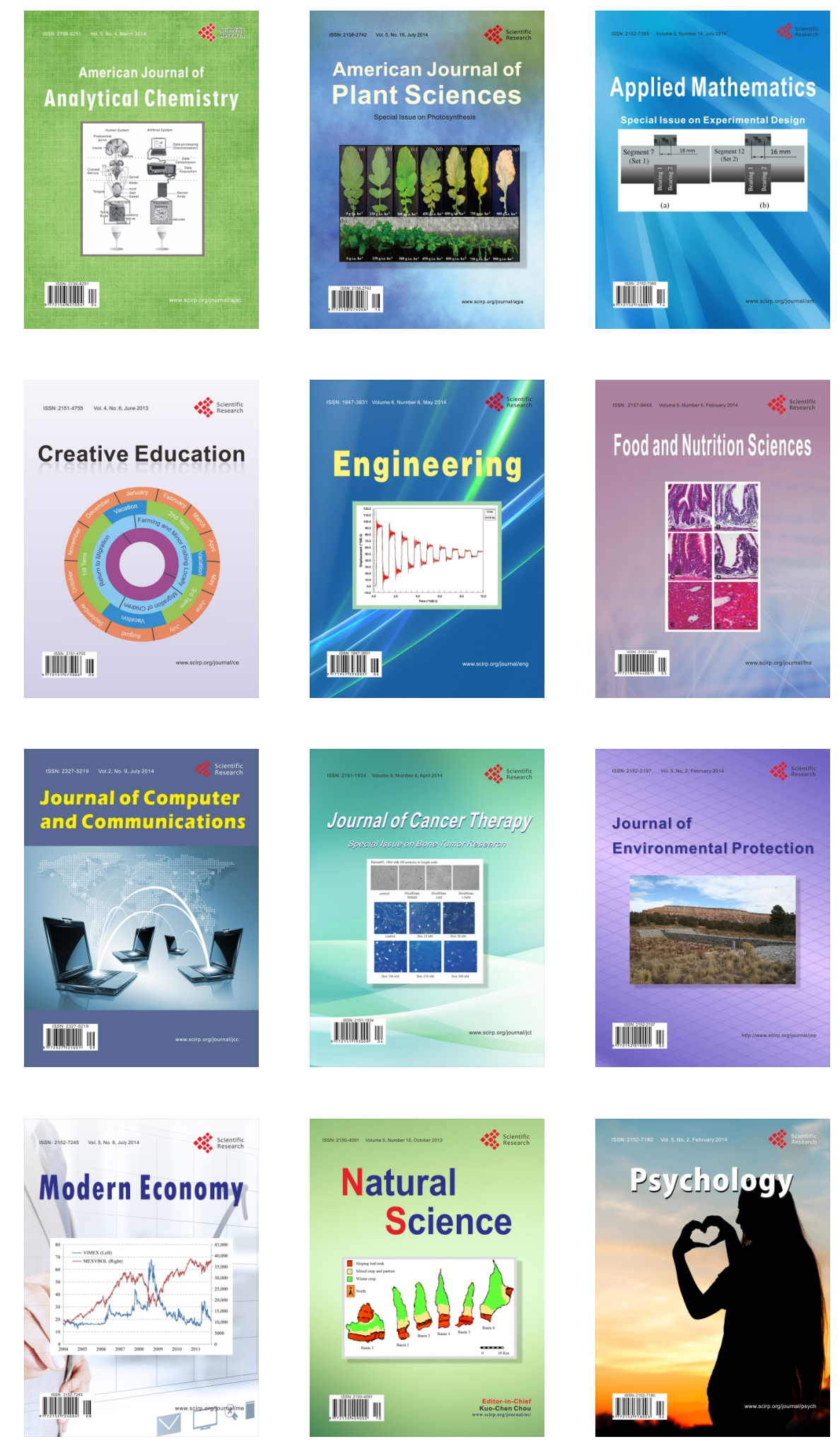